\title{
Methylmercury poisoning
}

\section{Clinical follow-up and sensory nerve conduction studies}

\author{
RUSSELL D. SNYDER ${ }^{1}$ AND DON F. SEELINGER \\ From the Department of Neurology, University of New Mexico, School of Medicine, \\ Albuquerque, New Mexico, USA
}

SYNOPSIS Methylmercury poisoning occurred in four cases after passage of methylmercury through the food chain. The neurological damage in all four cases was severe. The damage was greater at younger ages with maximum involvement in the case of transplacental poisoning. Significant recovery occurred in two cases, but on six-year follow-up two cases remained severely impaired. Clinical and electrophysiological evidence suggests that damage to peripheral sensory nerves may not be the cause of the late sensory symptomatology.

In August 1969 a part-time farmer in Alamogordo, New Mexico, inadvertently began to feed his pigs with seed grain which had been treated with a methylmercury fungicide. Beginning in September 1969, the meat from one of these pigs was consumed by a family of 10 persons. In December 1969 three family members (aged 8, 13 , and 20 years) developed ataxia, agitation, visual impairment, and impaired consciousness. Their urine mercury levels were elevated and high levels of mercury were found in the meat and grain (Curley et al., 1971). These three family members received a course of chelation therapy and stopped eating the meat (Pierce et al., 1972).

When the family began to consume the mercury-containing meat, the mother, 40 years of age, was three months pregnant. Subsequently, a male infant was delivered at term with elevated urine mercury levels. By 3 months of age the infant was hypotonic, irritable, without evidence of visual fixation, and was having myoclonic seizures (Snyder, 1971).

This report concerns a six-year follow-up of the poisoned family members with data regarding sensory nerve conduction studies.

\footnotetext{
1 Address for reprints: Dr Russell D. Snyder, Department of Neurology, University of New Mexico School of Medicine, Albuquerque, NM 87131, USA.

(Accepted 16 March 1976.)
}

\section{CASE REPORTS}

CASE 1 The congenital case, now 6 years of age, displays severe neurological impairment manifested by blindness, myoclonic seizures, and spastic quadriparesis. Tendon reflexes are increased. $\mathrm{He}$ is not rolling over, shows only minimal awareness of his environment, and has no speech.

CASE 2 The younger child, a girl, now 14 years of age, is blind, unable to sit unsupported or to roll over, unable to hold objects, incontinent of urine and faeces, and has no speech. Tendon reflexes are increased. She has occasional tonic seizures.

CASE 3 The middle child, a boy, now 19 years of age, partially recovered during the first 18 months after the onset of his illness. His intellect appears preserved. Visually he can only distinguish light and dark. Hearing is normal. Position sense, two-point discrimination, and stereognosis are markedly decreased with normal touch, pain, temperature, and vibration sense. Choreoathetoid movements and ataxia are present in the upper extremities. He is able to walk unassisted for short distances with severe truncal ataxia. A mild right hemiparesis is present. Tendon reflexes are normal. He has had no seizures. Speech is clear.

CASE 4 The oldest of the originally affected cases, now a woman 26 years of age, also partially recovered during the first 24 months after the onset of her illness. Tunnel vision is present. Hearing is normal. 
Position sense, two-point discrimination, and stereognosis are markedly decreased with normal touch, pain, temperature, and vibration sense. She is able to walk but has truncal ataxia. Athetosis is present in the upper extremities. Tendon jerks are normal. She has had no seizures. Speech is slurred. She complains of numbness and tingling in her extremities.

\section{SPECIAL STUDIES}

Electrophysiological studies were performed on peripheral nerves five years after the poisoning. A Medic Flexline-S dual channel electromyograph was used for the testing.

In the right median nerve, antidromic sensory latencies and conduction velocities were measured. Stimulation sites were at the wrist and elbow while recording from a clip ring electrode on the index finger. In the older patients a standard distance of $14 \mathrm{~cm}$ was used between the stimulating electrode and the pickup electrode on the index finger. Supramaximal stimulation was used. Latencies were measured to the peak of the negative deflection. Values obtained were considered normal (Goodgold and Eberstein, 1972) (Table).

Orthodromic sensory latencies were obtained from the right median nerve. In the older patients a standard distance of $14 \mathrm{~cm}$ was used between the stimulating electrode on the index finger and the proximal recording electrode at the wrist. The stimulus was applied by a ring electrode and was

TABLE

ELECTROPHYSIOLOGICAL STUDIES

\begin{tabular}{|c|c|c|c|c|c|}
\hline & \multicolumn{5}{|c|}{ Case number } \\
\hline & 1 & 2 & 3 & 4 & $5^{*}$ \\
\hline \multicolumn{6}{|l|}{ Median nerve, sensory conduction } \\
\hline Antidromis latency, wrist (ms) & $t$ & 3.6 & 2.7 & 3.0 & 3.4 \\
\hline Antidromic latency, elbow (ms) & $\dagger$ & 6.2 & 5.7 & 6.4 & 7.1 \\
\hline Antidromic sensory velocity $(\mathrm{m} / \mathrm{s})$ & $\dagger$ & 46 & 71 & 58 & 58 \\
\hline Orthodromic latency, wrist (ms) & 2.3 & 2.2 & 2.5 & 2.8 & 2.7 \\
\hline \multicolumn{6}{|l|}{$\begin{array}{l}\text { Common peroneal nerve, antidromic } \\
\text { conduction }\end{array}$} \\
\hline Latency (ms) & 3.1 & 4.1 & 5.2 & 6.0 & 6.0 \\
\hline Surface distance $(\mathrm{cm})$ & 15 & 25 & 27 & 32.5 & 33 \\
\hline \multicolumn{6}{|l|}{$\begin{array}{l}\text { Posterior tibial, motor, and sensory } \\
\text { conduction }\end{array}$} \\
\hline Latency onset ' $M$ ', ankle (ms) & 2.1 & 3.3 & 3.1 & 5.1 & 4.5 \\
\hline Latency onset 'H', ankle (ms) & 26.1 & 35.8 & 38.4 & + & + \\
\hline Latency onset ' $M$ ', knee (ms) & 5.6 & 10.2 & 9.7 & 12.0 & 10.9 \\
\hline Latency onset ' $H$ ', knee (ms) & 21.1 & 28.5 & 31.9 & + & + \\
\hline Motor conduction velocity $(\mathrm{m} / \mathrm{s})$ & 55 & 49 & 45.7 & 52 & 56 \\
\hline Sensory conduction velocity $(\mathrm{m} / \mathrm{s})$ & 39 & 46.5 & 45.4 & + & + \\
\hline
\end{tabular}

* Mother of cases 1-4, neurologically intact, aged 46 years.

† Technically not recordable. supramaximal. Pickup electrodes were Hewlett Packard surface electrodes, applied snugly with a tape. Measurements were made to the peak of the negative deflection. Values obtained were considered normal (Table).

In the right common peroneal nerve combined orthodromic sensory and antidromic motor nerve conduction velocities were obtained with the stimulus applied to the anterolateral aspect of the distal portion of the leg. Pickup electrodes were two needle electrodes applied subcutaneously $4 \mathrm{~cm}$ apart at the head of the fibula overlying the course of the common peroneal nerve. The latencies were measured to the peak of the negative deflection.

Sensory nerve conduction velocities were measured in the posterior tibial nerve by an alternative method (Wager and Buerger, 1974). A surface electrode was placed over the intrinsic foot musculature on the medial aspect of the foot. Both $\mathrm{M}$ - and $\mathrm{H}$-response latencies were measured, with stimulation sites at the tarsal tunnel and in the popliteal fossa. Utilizing the difference in the latency for the H-reflex and making a calculation considering the distance between the more distal and more proximal stimulation sites, nerve conduction velocities were calculated and interpreted as being sensory nerve conduction velocities. Motor nerve conduction velocities were also obtained from the posterior tibial nerve. Values were considered to be normal (Table).

\section{DISCUSSION}

This family represents an example of the consequences of inadvertent misuse of seed grain treated with methylmercury. The methylmercury produced poisoning after passage through the food chain. The episode can be added to the international list of catastrophic illnesses produced by organic mercury. Episodes of organic mercury poisoning have been reported in Japan (Kurland et al., 1960), Iraq (Jalili and Abbasi, 1961), Pakistan (Haq, 1963), and Guatemala (Ordonez et al., 1966). A second epidemic has occurred recently in Iraq (Bakir et al., 1973).

In our series severe neurological damage was present in the involved individuals. The damage was greater at younger ages with maximum damage in transplacental poisoning. The milder cases displayed progressive and significant recovery after the poisoning.

Sensory symptomatology consisting of numbness and tingling of the distal extremities, lips, and tongue has been a major presenting symptom 
of methylmercury poisoning (Hunter et al., 1940; McAlpine and Araki, 1959; Kurland et al., 1960). This type of symptomatology is generally considered to indicate peripheral nerve disease. Experiments with rats have demonstrated selective toxicity of methylmercury to axons and myelin of sensory nerve fibres (Miyakawa, et al. 1970; Miyakawa et al., 1974), and to dorsal root ganglia (Herman et al., 1973; Somjen et al., 1973). However, rats may be inappropriate experimental models for methylmercury poisoning in humans (Berlin et al., 1975).

The two of our patients on whom detailed sensory examination was possible demonstrated a peculiar dissociated sensory loss on five-year follow-up. Touch, pain, temperature, and vibration sense were preserved with marked loss of position sense, two-point discrimination, and stereognosis. The relatively normal sensory and motor nerve conduction velocities in all our patients (Table) and the preservation of deep tendon reflexes provide evidence suggesting that the late sensory symptomatology of methylmercury poisoning may not be on the basis of peripheral nerve lesions (LeQuesne et al., 1974; Rustam and Hamdi, 1974). The combination of findings on sensory examination is more compatible with a cortical aetiology.

Peripheral nerve abnormalities have not been demonstrated electrophysiologically in humans with methylmercury poisoning (LeQuesne et al., 1974; Pazderova et al., 1974; Von Berg and Rustam, 1974). A recent report has suggested that some patients may have abnormalities at the myoneural junction (Rustam et al., 1975). Necropsy studies from the extensive Japanese experience with methylmercury poisoning have revealed peripheral nerves which were almost free of alterations but significant loss of neurones and gliosis in the postcentral gyrus (Shiraki and Takeuchi, 1971).

Perhaps methylmercury has an early reversible effect on peripheral nerves but in chronic human cases produces sensory symptomatology on the basis of lesions in the postcentral gyrus. These findings raise the possibility that the athetoid movements which have been described in methylmercury poisoning (Kurland et al., 1960; Snyder, 1972) are not manifestations of a true athetosis, but rather manifestations of a pseudoathetosis secondary to the sensory disturbance.

\section{REFERENCES}

Bakir, F., Damluji, S. F., Amin-Zaki, L., Murtadha, M., Khalidi, A., Al-Rawi, N. Y., Tikriti, S., Dhahir, H. I., Clarkson, T. W., Smith, J. C., and Doherty, R. A, (1973). Methylmercury poisoning in Iraq. Science, 181, 230-241.

Berlin, M., Grant, C. A., Hellberg, J., Hellstrom, J., and Schutz, A. (1975). Neurotoxicity of methylmercury in squirrel monkeys. Archives of Environmental Health, 30, 340-348.

Curley, A., Sedlak, V. A., Girling, E. F., Hawk, R. E., Barthel, W. F., Pierce, P. E., and Likosky, W. H. (1971). Organic mercury identified as the cause of poisoning in humans and hogs. Science, 172, 65-67.

Goodgold, J., and Eberstein, A. (1972). Electrodiagnosis of Neuromuscular Diseases, p. 91, Williams and Wilkins: Baltimore.

Haq, I. U. (1963). Argosan poisoning in man. British Medical Journal, 1, 1579-1582.

Herman, H. P., Klein, R., Talley, F. A., and Krigman, M. R. (1973). An ultrastructural study of methylmercury-induced primary sensory neuropathy in the rat. Laboratory Investigations, 28, 104-118.

Hunter, D., Bomford, R. R., and Russell, D. S. (1940). Poisoning by methylmercury compounds. Quarterly Journal of Medicine, 9, 193-213.

Jalili, M. A., and Abbasi, A. H. (1961). Poisoning by ethyl mercury toluene sulphonanilide. British Journal of Industrial Medicine, 18, 303-308.

Kurland, L. T., Faro, S. N., and Siedler, H. (1960). Minamata disease: The outbreak of a neurologic disorder in Minamata, Japan, and its relationship to the ingestion of seafood contaminated by mercuric compounds. World Neurology, 1, 370-395.

LeQuesne, P. M., Damluji, S. F., and Rustam, H. (1974). Electrophysiological studies of peripheral nerves in patients with organic mercury poisoning. Journal of Neurology, Neurosurgery, and Psychiatry, 37, 333-339.

McAlpine, D., and Araki, S. (1959). Minamata disease. Archives of Neurology (Chic.), 1, 522-530.

Miyakawa, T., Deshimaru, M., Sumiyoshi, S., Teraoka, T., Udo, N., Hattori, E., and Tatetsu, S. (1970). Experimental organic mercury poisoning. Acta Neuropathologica (Berl.), 15, 45-55.

Miyakawa, T., Sumiyoshi, S., and Deshimaru, M. (1974). Late changes in sciatic nerve of rats after a small dose of methyl methylmercury sulfide. Acta Neuropathologica (Berl.), 30, 33-41.

Ordonez, J. V., Carillo, J. A., Miranda, M., and Gale, J. L. (1966). Epidemiological study of an illness in the Guatemala highlands believed to be encephalitis. Boletin de la Oficina Sanitaria Panamericana, 60, 18-24.

Pazderova, J., Jirasek, A., Mraz, M., and Pechan, J. (1974). Postmortem findings and clinical signs of dimethyl mercury poisoning in man. Internationales Archiv fur Arbeitsmedizin, 33, 323-328. 
Pierce, P. E., Thompson, J. F., Likosky, W. H., Nickey, L. N., Barthel, W. F., and Hinman, A. R. (1972). Alkyl mercury poisoning in humans. Journal of the American Medical Association, 220, 1439-1442.

Rustam, H., and Hamdi, T. (1974). Methyl mercury poisoning in Iraq. Brain, 97, 499-510.

Rustam, H., Von Berg, R., Amin-Zaki, L., and El Hassani, S. (1975). Evidence for a neuromuscular disorder in methylmercury poisoning. Archives of Environmental Health, 30, 190-195.

Shiraki, H., and Takeuchi, T. (1971). Minamata Disease. In Pathology of the Nervous System, pp. 1651-1665. Edited by J. Minkler. McGraw-Hill: New York.

Snyder, R. D. (1971). Congenital mercury poisoning. New England Journal of Medicine, 284, 1014-1016.
Snyder, R. D. (1972). The involuntary movements of chronic mercury poisoning. Archives of Neurology (Chic.), 26, 379-381.

Somjen, G. G., Herman, S. P., and Klein, R. (1973). Electrophysiology of methylmercury poisoning. Journal of Pharmacology and Experimental Therapeutics, 186, 579-592.

Von Berg, R., and Rustam, H. (1974). Electrophysiological investigations of methylmercury intoxication in humans. Evaluation of peripheral nerve by conduction velocity and electromyography. Electroencephalography and Clinical Neurophysiology, 37, 381-392.

Wager, E. W., and Buerger, A. A. (1974). A linear relationship between H-reflex latency and sensory conduction velocity in diabetic neuropathy. Neurology (Minneap.), 24, 711-714. 